\title{
LA CHINGANA COMO CANON CULTURAL. HACIA UNA CRÍTICA DE LOS ESPACIOS FESTIVOS TRADICIONALES EN LA MUSICOLOGÍA E HISTORIOGRAFÍA CHILENAS DEL SIGLO XIX*
}

\author{
THE CHINGANA AS A CULTURAL CANON. TOWARDS A CRITIQUE \\ OF TRADITIONAL FESTIVE SPACES IN 19TH CENTURY CHILEAN \\ MUSICOLOGY AND HISTORIOGRAPHY
}

\author{
Christian Spencer-Espinosa**
}

\begin{abstract}
El objeto de este texto es demostrar el carácter canónico adquirido por la chingana como objeto de estudio académico en la historiografía de la música y la musicología chilena de las últimas décadas. Mi interés es, por un lado, destacar el trabajo realizado por un conjunto de historiadores/as de la cultura y las mentalidades acerca de la cultura popular santiaguina del siglo XIX, y, por otro, reparar en la poca atención que estos han prestado a otros espacios de características similares a la chingana, posiblemente debido a la falta de integración de una teoría del espacio relacional.

El texto está organizado en cuatro partes. En la primera explico la consolidación de la chingana como objeto de estudio académico. En la segunda analizo el modo en que esta se ha convertido en canon histórico musical y las razones que podrían explicar este fenómeno (abundante información en archivos, necesidad de control legal y gravamen y la ausencia de teorías del espacio). En la tercera parte ofrezco reflexiones exploratorias acerca de cuáles serían los lugares postergados por la historiografía y la musicología, instalando algunos conceptos que pueden ser útiles para examinar la dimensión espacial de la cultura, como "lugar" y "sentido de lugar". La última parte del artículo son las conclusiones, donde sintetizo algunas de las ideas principales y comento la necesidad de evitar una "hermenéutica monoespacializada" en el estudio de las diversiones públicas. Para ello propongo el análisis relacionado de los espacios de entretención entendidos como circuitos de cultura y no como territorios aislados de expresión comunicativa.

Palabras claves: Chingana, historiografía chilena, cultura popular, archivo, lugar.
\end{abstract}

The main goal of this article is to demonstrate the canonical character acquired by the "chingana" as an object of academic study in the historiography of Chilean music and musicology in recent decades. I aim to highlight the work carried out by a group of historians of culture and mentalities on the popular culture of Santiago of the 19th century, but also to the call the attention about other spaces -similar to chingana- not included in history due to the lack of integration of a relational space theory.

The text is organized in four parts. First, I explain the consolidation of the chingana as an object of academic study. In the second, I analyze the way in which this place has become a musical and historical canon and the reasons that could explain this phenomenon (information in archives, legal control and taxation, and the absence of theories of space). In the third part, I offer preliminary ideas about which places would be postponed by historiography and musicology, installing some concepts that may be useful to examine the spatial dimension of culture, such as "place" and "sense of place". In the conclusions I synthesize some of the main ideas and establish the need to avoid a "monospatialized hermeneutics" of place in the study of public entertainment. For this I propose the analysis of entertainment spaces understood as "circuits of culture" and not as isolated territories of communicative expression and art.

Key words: Chingana, Chilean historiography, popular culture, archive, place.

\section{Introducción}

Chingana o chinkána en quechua, significa "escondrijo" o "lugar para ocultarse" (Garrido, 1943: 70; Salinas, 2000: 64; Rodríguez, 1885). Los primeros datos que conocemos de ellas datan del siglo XVI como construcciones de ramadas para los pasatiempos y juegos coloniales de la época. Oreste Plath (1965: 20) nos informa que no solo existieron en Chile, sino también en Perú y otros lugares de América. Entre las décadas de 1670 y 1680 figura una ramada a la que asistieron los Oidores

\footnotetext{
* Este artículo se enmarca en el Proyecto FONDECYT No 1161532 "Hacia una sociología de la cultura popular ausente. Corporalidad, representación y mediatización de 'lo popular reprimido' y 'lo popular no representado' en Santiago de Chile (1810-1925)”, 2016-2020, con la participación de Chiara Sáez (Investigadora principal) y Antonieta Vera (coinvestigadora).

** Universidad Mayor, Centro de Investigación en Artes y Humanidades (CIAH), Facultad de Humanidades. Santiago, Chile. Correo electrónico: canazo@gmail.com
} 
de la Real Audiencia del Reino de Chile que sería equivalente a una chingana (Garrido, 1979: 176), pero luego se pierden los datos específicos de su existencia hasta el siglo XIX, cuando reaparece con fuerza y cierto carácter masivo. En la década del 20 de este siglo las chinganas se institucionalizan en el departamento de Santiago por medio de una norma destinada a regular las diversiones (Purcell, 2000a: 214). Su apariencia física es la de una tienda improvisada hecha con ramas, a veces llamada parral (Pereira, 1941: 251), por lo que su permanencia en el tiempo no parece posible. Sin embargo, el pueblo las construye año y tras año y hacia la década del 30 su expansión y constante aparición la convierte en el principal espacio -junto con el teatro- para la sociabilidad, particularmente para la exposición de ciertos géneros musicales como la zamacueca y otros bailes de tierra. En 1831, el memorialista Rafael Valdés señala que en Santiago había más de cuarenta chinganas que describe como lugares indecentes donde la gente va solamente a beber alcohol y embriagarse (Amunátegui en Pereira 1941: 272). Al sobrepasar el medio siglo comienzan a hacerse conocidos algunos barrios que cuentan con una nutrida presencia de chinganas, como el sector ubicado al norte del Río Mapocho -que divide la ciudad de sur a norte- llamado La Chimba, cuyo significado es literalmente "la otra parte". Como señala Salinas, en el contexto colonial y postcolonial la chingana significó "fiesta de gente ordinaria con baile y música" donde "se interpretaron las danzas y las músicas que serían reprobadas sobre todo por el canon ilustrado" (2000: 64). Aunque la elite pipiola y pelucona criticó la chingana y la consideró inmoral e ilegal (Donoso 2009), fue siempre vista como "un espacio de libertad, cultural, lingüística y corporal intolerable", lugar "privilegiado" para la emergencia de manifestaciones populares diversas, desde la música hasta la religión popular (Salinas 2000).

En los últimos tiempos la chingana ha entrado en el mundo académico con extraordinaria fuerza. Desde hace más de una década que es considerada el eje de la cultura popular del siglo XIX o al menos una práctica cultural central del bajo pueblo chileno. Libros, artículos y ponencias escritas desde la historiografía de la música, la cultura y las entretenciones, así como desde la musicología, muestran una marcada tendencia a considerar a la chingana como el principio ordenador de la diversión pública decimonónica. ¿Qué condición ostentaba la chingana que permitió asignarle este valor de principio articulador de la cultura popular? ¿Qué relación tuvo con el bajo pueblo?

El bajo pueblo es -en palabras de Pinto y Salazar (1999)-el sujeto social cuya historicidad no ha sido reconocida pero que posee capacidad de organización, conciencia de su subordinación y potencial para trabajar en función de proyectos alternativos al orden establecido. La chingana, entendida como una taberna (techada o no, permanente o improvisada) donde se bebe, baila o come, habría sido el lugar donde este bajo pueblo habría vivido sus horas de diversión y ocio durante el Santiago del siglo XIX. La asociación entre estos dos elementos, pueblo y fiesta, es justificada no solo por la enorme cantidad de referencias que existen respecto de ella en las regulaciones públicas, sino también por su extensa presencia en la pintura, la poesía popular y el canto a lo poeta, entre otras muchas expresiones culturales de esta época. Existe además una asociación indirecta entre el carácter lascivo y preilustrado de la chingana con la idea misma de pueblo, en el sentido de que los salones eran para la elite mientras que el pueblo "no educado" asistía a las chinganas, verdaderas "escuelas de vicio" según las palabras del jurista gaditano que viviera en Chile, José Joaquín de Mora (Pereira 1941: 254).

En la historiografía de la música la correlación entre pueblo y chingana es notoria y podemos apreciarla en la obra de investigadores fundacionales de esta disciplina, como Eugenio Pereira Salas (1941) y Pablo Garrido (1943), pero también en la obra de historiadores posteriores, como Jaime Valenzuela (1992) y Maximilano Salinas (2006), y en la nueva historia social, como Fernando Purcell (1998 y 2000), Igor Goicovic (2005), Karen Donoso (2009) y Sebastián Rico (2009), entre otros. En la musicología la chingana también ha ocupado este estatus de espacio propio del pueblo, según lo expresan Pablo Garrido (1976, 1979), Carlos Vega (1953: 66), Rodrigo Torres (2001: 10-11), Salinas en algunos de sus textos inclinados hacia la música (Salinas 2000), Izquierdo, Jordán y Torres (2016) y yo mismo en mi trabajo publicado en 2007 en formato de tesis (2007a) y artículo (2007b), entre otros. Inclusive dentro del campo de la arquitectura se han escrito trabajo que realzan el carácter de tejido "vegetal" y al mismo tiempo "social" de la chingana en tanto espacio de integración social (Torres 2019). Todos estos textos han aportado una arista fundamental para comprender este sitio como uno de los pilares espaciales de la cultura chilena del 
siglo XIX. Por un lado, han descrito históricamente su aspecto físico, dando cuenta de su cambio de ramada "campesina" y "agreste" a parral o baño privilegiado para la convivencia festiva. Por otro, han hecho hincapié en su condición de espacio "situado" compuesto por sujetos de carne y hueso que pasaban horas de su vida charlando, bebiendo, cantando, bailando, y, en algunos casos, ejerciendo el comercio sexual.

Partiendo del reconocimiento de estos trabajos, este artículo tiene el objetivo de demostrar el carácter canónico que fue adquiriendo la chingana como espacio para la interpretación de la cultura chilena, sobre todo en los últimos años en que se ha consolidado como objeto de estudio académico. Mi interés es llamar la atención acerca de otros espacios de ocio aparentemente similares a la chingana cuya descripción y puesta en valor ha sido postergada por la historiografía chilena de la música y la cultura, así como por la musicología. Mi intención no es cuestionar el concepto de pueblo utilizado por la historiografía ni dudar acerca de su interpretación de los archivos, sino ofrecer una mirada más abierta y sociológica de la cultura popular con un concepto de espacio más amplio que permita comprender la chingana como parte de un sistema de diversiones interrelacionado y abierto. El texto está dividido en cuatro partes: en la primera explico la consolidación de la chingana como objeto de estudio académico. En la segunda analizo el modo en que esta se convierte en paradigma o canon de la cultura decimonónica santiaguina, señalando tres razones que podrían explicar este fenómeno (la abundante información acerca de ella en los archivos, la necesidad de control legal y gravamen y la ausencia de teorías del espacio). Y en la tercera, ofrezco algunas reflexiones exploratorias acerca de cuáles serían los lugares postergados por la historiografía y la musicología, mencionando algunas ideas pertenecientes a las teorías del espacio como "lugar" y "sentido de lugar". La última sección son las conclusiones, donde sintetizo algunas de las ideas principales y comento la necesidad de evitar una "hermenéutica monoespacializada" de las diversiones públicas por medio de un análisis relacionado de los espacios de entretención.

Antes de partir quisiera hacer dos observaciones metodológicas. La primera es que el texto se basa en la revisión de fuentes de la Intendencia y Municipalidad de Santiago, así como de otros archivos relevantes, y la selección de noticias relativas a las diversiones populares entre la década de 1810 y 1870. La selección de los documentos estuvo basada en el marco teórico del proyecto de investigación ya señalado al inicio, orientado a conocer la cultura popular santiaguina del siglo XIX en sus dimensiones corporales, mediáticas y de representación ${ }^{1}$.

La segunda observación es que este artículo se concentra en los textos producidos por historiadores de la cultura o las mentalidades y el trabajo de algunos musicólogos. No abordo el trabajo histórico realizado por folcloristas importantes como Oreste Plath, Juan Guillermo Prado, Pablo Garrido o Manuel Dannemann, entre otros, por considerar que el foco de su atención no está puesto en la historiografía sino en los aspectos culturales de la tradición.

\section{La chingana como objeto de estudio}

En su libro Recuerdos de treinta años (18101840), de 1872, José Zapiola señala que las chinganas "en todo tiempo las había en gran número y en todos los barrios" donde "se agrupaba el populacho (y también la gente decente)" (Zapiola 1974: $32,154)$. Aunque este no es un texto académico, es una de las primeras referencias historizadas de las diversiones chilenas, por lo que puede considerarse una primera referencia de alcance intelectual importante. Posteriormente a este texto, la presencia de la chingana será debatida por musicólogos como Garrido (1943), Vega (1953) y Claro (1994), dramaturgos como Acevedo Hernández (1953) e historiadores como Pereira (1941), que repasarán también las abundantes crónicas de viajeros y memorialistas locales. Durante la segunda mitad del siglo XX la chingana será tratada de acuerdo con su relación con lo nacional y lo popular, siendo abordada por otros textos de Garrido (1976, 1979), y, más tibiamente, en las notas de revista de Durand (1954) y Plath $(1965,1970)$. Aunque Plath es folclorista y Durand un literato ensayista, ambos abordan la chingana como objeto cultural desde la música. En estos mismos años, aunque desde una perspectiva próxima al urbanismo, el historiador Armando de Ramón afirmará que las chinganas son espacios de sociabilidad de los habitantes urbanos, pero sobre todo lugares de "circulación de la cultura", ya que a partir de ellas el bajo pueblo va trasladando sus hábitos desde las zonas rurales hasta las urbanas (De Ramón, 1978: 266-270). 
Sin embargo, es a partir de la obra del historiador Jaime Valenzuela que la chingana se convierte en objeto de estudio estable y legítimo dentro de la historiografía de las mentalidades y las entretenciones, rebasando con creces su historización previa. Según Valenzuela, la chingana fue el lugar privilegiado de la convivencia popular que facilitó las relaciones interpersonales y el ocio. En ella "se completaban los elementos y las condiciones de la gran fiesta popular..." (Valenzuela, 1992: 378), por eso, sostenía, "La característica de ser centros de diversión con un contenido auténticamente popular hacía que las chinganas y ramadas se convirtieran en el fin último de la totalidad de los espectáculos y diversiones rurales" (p. 380, negritas mías). La chingana, entonces, fue el "genuino exponente de sociabilidad popular campesina, y la fuerza de las pautas de valor y conducta propias de esos sectores" (Valenzuela, 1992: 381). Con esta perspectiva, se transforma el estatus de la chingana de espacio de baile, libertad, alcohol y ocio, a lugar de sociabilidad y despliegue del sujeto popular del siglo XIX. De este modo, la chingana adquiere peso teórico para entrar en otras disciplinas como categoría explicativa de la sociabilidad y la diversión colectiva.

La continuación de esta perspectiva -de modo más profundo y documentado- tendrá lugar en la obra de los/las historiadores/as Fernando Purcell, Igor Goicovic, Sebastián Rico y Karen Donoso. Para estos/as cuatro intelectuales, la chingana es un objeto de estudio necesario para conocer la vida del bajo pueblo y estudiar sus modos de diversión en el siglo XIX. El análisis de estos/as autores/as parte de la base de que en la chingana se desenvuelve un sujeto histórico vinculado a las clases bajas (el bajo pueblo) que está inserto en la sociedad y posee una identidad dinámica (no fija) con elementos simbólicos y dramáticos (Pinto y Salazar, 1999: 96). Pero también asume que detrás de estas prácticas culturales de ocio y fiesta, hay señales fundamentales de la vida urbana santiaguina del siglo XIX, así como una relación entre cultura, Estado y nación. Aunque no todos/as autores/as sostienen esta perspectiva postmarxista de manera abierta, existe un reconocimiento explícito a la condición popular de las chinganas (ocupadas preferencialmente por estos sectores, sin perjuicio de que las clases altas pasearan por ellas de modo discontinuo) así como al deseo del Estado de regular su funcionamiento por medio de ordenamientos y licencias.
Para Purcell la chingana es un espacio del bajo pueblo que contribuye a la creación del imaginario nacional, aunque con tensiones que estiran su definición y carácter plurisocial (Purcell, 2007)2 ${ }^{2}$. En una línea similar, Donoso considera que mediante la chingana es posible "estudiar la dinámica de construcción de un discurso nacional" y así "desentrañar la formación y legitimación de este discurso, el cómo logra situarse y adquirir hegemonía en un proceso histórico específico" (Donoso, 2009: 89). Goicovic, por su parte, examina el rol de la mujer en la chingana insistiendo en su carácter popular y poco moral, pero particularmente en la regulación de la que fue objeto debido a la violencia permanentemente que en ella se incubaba. Estos sucesos ponen de manifiesto, dice Goicovic, "el alto grado de autonomía alcanzado por la cultura popular en sus ámbitos de sociabilidad" (2005, "5. La chingana o pulpería"). En el caso de Rico (2009), la chingana es considerada una metáfora del "encuentro y diferenciación en torno a la nación", cuyo trasfondo fue el cambio de lo popular en nacional. Donoso va más lejos y concibe la chingana como una suerte de impulso popular, un espacio para la tradición y un ambiente festivo que logró expandirse en las zonas urbanas capitalinas de las décadas del 20 al 40. El impacto de la chingana, en sus palabras, fue mucho más allá de las cuestiones eminentemente culturales:
"el ambiente chinganero logró penetrar hacia el centro de la ciudad, invadiendo los cafés y teatros, junto a su baile por excelencia, la zamacueca. Fue tal el impulso de estas formas que fueron integradas como parte de la cultura nacional y las fiestas cívicas, debido a que la elite no tuvo la capacidad de entregar un fundamento cultural a su discurso nacional. El discurso nacional fue creado por la elite para fortalecer y difundir su proyecto de nación, pero fueron las tradiciones populares las que le dieron un contenido real" (Donoso, 2009: 88)

Con el trabajo de Jimena Silva (2014), no obstante, la chingana adquiere su estatus más profundo como objeto de estudio para la historiografía de las mentalidades y las entretenciones. Según Silva, la chingana provee un tipo de identidad propia: la identidad "chinganesca" propia del bajo pueblo (p. $5,18,79)$, que es posible debido a que por medio 
de ella se pueden conocer las relaciones sociales de los sujetos populares en su vida cotidiana e "historicidad humanizante". La chingana, dice Silva, es un "espacio de formación de la propia cultura de estos sectores" (p. 108) capaces "de configurar su propio espacio socioeconómico y cultural" (p. 6) y proyectar su existencia desde ella. De este modo, Silva instala la chingana como un paradigma cultural para observar la cultura gracias a su condición aglutinadora ("un espacio de reunión de la familia, amigos, vecinos, y forasteros", p. 50), carácter plurisocial ("traspasó comportamientos y formas de subsistencia" (p. 31)) y condición enteramente popular ("fue el cuerpo donde se concentraron diversas actitudes, costumbres y comportamientos de los sectores populares... el centro de las rebeldías expresadas a través del bandolerismo, vagabundaje, marginación, ociosidad, alcoholismo", p. 82). La chingana, por tanto, sería el lugar para observar el sujeto histórico y popular:

"La constitución de un sujeto histórico como tal, es un proceso muy complejo, donde se explicará [sic] al sujeto a través de su accionar mismo, y bajo qué modos conscientes internaliza las estructuras generales (o estructuras de orden fáctico), con su propio modo de entender la realidad... la chingana fue el espacio donde los sectores populares se construyeron y desarrollaron en colectivo, proyectando su cotidianidad, sus redes, su cultura, su identidad, su ser, en realidad su vida por completo" (Silva 2014: 180)

\section{La chingana como canon de la cultura}

Durante los más de veinte años que van desde el texto de Valenzuela (1992) al de Silva (2014), la chingana se consolida como objeto de estudio de la musicología e historiografía chilenas ${ }^{3}$. Se legitima como espacio de observación de la cultura "auténticamente popular" (Valenzuela) donde el bajo pueblo escucha música, baila, bebe y ejerce "la prostitución" (Goicovic). Con ella se abre una perspectiva para la historia "de las mentalidades" o la "entretención" por medio de la cual se pueden abordar temas que desde la perspectiva sociopolítica del bajo pueblo salazariano son más difíciles, como el baile, la fiesta, las tensiones de género, las disputas por la representación simbólica de la nación (Rico) y la correlación directa entre el roto, el gañán o peón capitalino y la sociabilidad fuera de los espacios oficiales de la política. Del mismo modo, dentro de la musicología y la historia de la música la chingana será un antecedente histórico importante para el conocimiento del ambiente donde se hacía la música popular y tradicional (Pereira 1941, Spencer 2007a) y los espacios de "resistencia cultural" de ciertos barrios periféricos y suburbios de la capital (Torres 2001: 10-11).

¿Qué razones explican esta conversión de la chingana en objeto de estudio principal del mundo académico humanista? No existe una respuesta unívoca a esta pregunta, pero podemos señalar tres razones complementarias. La primera es la enorme abundancia de información que se produjo respecto de la chingana en la iconografía y la literatura chilenas, particularmente en crónicas de autores/as nacionales o de extranjeros/as, como las de Ignacio Domeyko, María Graham, Miguel Amunátegui y Vicente Pérez Rosales, entre otros. Estos relatos aportan datos descriptivos acerca de la chingana y observaciones (con intención etnográfica) de la vida de la población chilena en el espacio público y privado. Estas últimas amplifican además los prejuicios de los sectores acomodados, los intelectuales y los extranjeros, realizando aseveraciones relativas a la moral y la higiene que luego serán deconstruidas notablemente por la historiografía para detectar el discurso colonialista en las clases subalternas y construir un sujeto histórico limpio de estos prejuicios.

Este primer punto está relacionado con la importancia del archivo y la memoria en la investigación de cultura popular latinoamericana y chilena. De acuerdo con Ruz y Galdames (2014: 3), el archivo en su versión moderna es "el conjunto de testimonios, huellas, símbolos, monumentos, imágenes o sonidos, organizados con carácter de unidad" para el registro material del pasado. El archivo es también el interlocutor principal para edificar "modelos de análisis y de comprensión", por lo que se vuelve el medio legitimador de los postulados científicos del pasado, esto es, el validador de "apropiaciones subjetivas o colectivas respecto del pasado, demandadas por la ciudadanía y por especialidades que escapan al prototipo de las ciencias, pero que requieren de materialidad para adquirir valor testimonial" (Ibíd., p. 4). Como señalan estos autores, la búsqueda de la materialidad por medio del archivo es una respuesta a la urgencia de representar la 
"realidad social, cultural, política o institucional en dimensiones objetivas, pero también subjetivas e intersubjetivas" frente a los giros bidireccionales ocurridos en la historiografía hacia la antropología, la lingüística, la semiología, las visualidades y los enfoques críticos (Ibíd.). La chingana, en este sentido, sería una manera efectiva de obtener un testimonio "material" en el campo de la cultura, donde estos hechos son más difíciles de objetivar porque pueden tener también un carácter simbólico. La chingana vendría a aglutinar en un mismo lugar elementos festivos o carnavalescos (danza, música), formas de uso del cuerpo (performance), una distribución geográfica concreta y otras prácticas propias de los sectores populares (bandidaje, el consumo de alcohol, la violación de la ley y otros rasgos ampliamente estudiados por la historiografía), por lo que sería un modo de centralizar el estudio de la cultura popular en un objeto y espacio concretos. Extrapolando las ideas de Ruz y Galdames (2014: 5), esto satisfaría la demanda de pasado de la sociedad contemporánea, aunque exponiéndose a la nostalgia y la "saturación de memoria".

Si bien el archivo es un lugar de acumulación de la memoria, también es un "espacio de olvido" gracias a su técnica de repetición y exterioridad (Derridá 1997). El requisito de un espacio acotado (en el siglo XIX) y la posibilidad de incluir solo algunos elementos hacen que el estar "dentro del archivo" sea igual de importante que estar "fuera del archivo". En pocas palabras, así como contiene, el archivo también expulsa. Es la distinción griega entre mnéme o anámnesis (hypómnema) frente a la que el archivo ofrece una cara de preservación material y otra de hipomnemia, "no habría deseo de archivo sin la finitud radical, sin la posibilidad de un olvido..." (p. 11), en otras palabras, "El archivo trabaja siempre y a priori contra sí mismo" (p. 19-20). Desde la perspectiva de la relación entre performance y archivo, Diana Taylor señala que este salvaguarda la cultura impresa y material (los objetos) pero no puede desprenderse del repertorio en tanto "acto de transferencia corporalizado" de esa materialidad, es decir, debe incluir la actividad cognitiva y corporalizada de los sujetos para evitar el peligro de representar más al individuo (documento) que al colectivo (memoria) (Taylor 2017: 18-19). Por tanto, si el archivo incluye/excluye y corre el peligro de centrarse en la unidad (individuo, lugar), vale la pena preguntarse qué geografías de la cultura son excluidas y pensar la manera en que puedan ser reconsideradas para entrar de mejor manera a los intersticios de la historia cultural. En la sección siguiente volveré a este punto.

Una segunda razón para la canonización de la chingana es el hecho de que fuera objeto de regulaciones (a la diversión pública y el orden moral) y de impuestos específicos (por medio de licencias) desde al menos 1812 (Purcell, 2007: 192). Al aplicarse un control severo sobre la chingana y las características físicas y morales de quienes asistían a ellas, el Estado y el poder judicial juzgaron la cultura popular como problemática e instalaron gradualmente un ethos del comportamiento de la población. En la práctica, como expresa Bowen, esto convirtió la cultura popular en una dicotomía civilización/barbarie en donde la chingana representaba la "costumbre propia de pueblos bárbaros" y el teatro la "diversión civilizada (para las elites letradas)" (Bowen 2016: 45). Para efectos del argumento que aquí estoy exponiendo, lo que quiero destacar es que la chingana se convirtió en un punto de entrada historiográfico para los debates pertinentes al concepto de cultura popular, incluyendo las cuestiones relativas a la subalternidad y las prácticas culturales ubicadas fuera del ámbito de las clases dominantes, hegemónicas o aristocráticas.

Una tercera razón para la canonización de la chingana fue la relegación a un segundo plano de otros espacios de diversión popular. Desde mi punto de vista, esto se produjo debido a la poca importancia que la historiografía y la musicología le dieron a las teorías del espacio, abordando con preferencia aspectos materiales y dejando de lado aspectos psicoafectivos de la cultura, como el desarrollo de un "sentido de lugar" (apego sobre el espacio) o la economía política surgida de la interacción entre varias diversiones populares en la ciudad para cierta épocas del año. Volveré a este punto en la sección siguiente.

Las tres razones que he mencionado -abundante información, formas de control y ausencia de teorías del espacio- hicieron que la chingana alcanzara el estatus de "arista fundamental de la cultura chilena" y se convirtiera en un espacio canónico de la cultura chilena. Por canónico me refiero a dos cosas: la primera es la condición de "superviviente" de la cultura, como la define Bloom (1995), es decir, aquel conjunto de elementos cuyas "cualidades eternas y dimensiones trascendentales" merecen ser perpetuadas de alguna manera (Beard 
y Gloag, 2005: 33). Desde el punto de vista de la música, esto se refiere al acto de canonizar o seleccionar una obra "por medio de un juicio funcional, estético e histórico que permite dejar otras obras fuera de ese círculo virtuoso (Merino, 2006: 27). La segunda es el canon entendido como "conjunto de discursos" sobrevivientes respecto de la cultura que han logrado repetirse y traspasarse con el paso del tiempo, estableciendo algún régimen de verdad apreciado por miembros de la misma disciplina (Spencer 2009). El canon, al igual que el archivo, es una manera de incluir y excluir objetos dentro de un proceso de universalización de un repertorio textual o sonoro o, como en este caso, dentro de un espacio físico acerca del que se han construido historias sonoras (repertorios, bailes) y discursos. Revisemos a continuación qué espacios fueron dejados de lado dentro del discurso historiográfico y musicológico de la cultura del siglo XIX y por qué el concepto de espacio es relevante para comprenderlos.

\section{Los lugares postergados de la historiografía y la musicología}

En su origen, el espacio es un sitio vacío, inhabitado, erial o yermo que se va humanizando a medida que en él se desarrollan experiencias significativas (Aguilar, 2012: 122; Appadurai, 1996: 178-180). La habitación de los lugares hace que lo local esté siempre en constante construcción y perpetua tensión, por eso lo local es siempre relacional en el sentido de estar mediado por la interacción social y el modo en que los estímulos -como el baile o la música- pueden articularlo, visibilizarlo e incluso clausurarlo o determinarlo. Los lugares se crean (fundan, nacen) o se recrean (usan, reutilizan, revisitan) a partir de la relación que los sujetos o los colectivos establecen con el espacio y la manera en que estos permiten vivir la circunstancia cotidiana (Giglia 2012). Un "lugar", entonces, es aquel sitio donde se participa de una experiencia multisensorial individual, biológica, social y espacial que se encarna en algo "físico" que, en este caso, es la música, el baile o el discurso dentro de las chinganas (Aguilar 2012, Giglia 2012 y Wissmann 2014: 17-20).

Los lugares no nacen, sino que se "construyen" a medida que se va creando un sentido de pertenencia a él, llamado sentido de lugar, es decir, se van acumulando significados que producen apego y seguridad territorial. El sentido de lugar es un sentimiento de pertenencia subjetivo, emocional y afectivo que tiene impacto en la cultura, aun siendo tenue o transitorio (Connell y Gibson 2003, Tapia 2013). Precisamente, la apropiación de un lugar de diversión por parte de músicos, públicos, inspectores dueños de restaurantes, etc., genera un sentido de lugar que contribuye a desarrollar una red interconectada de sitios dedicados al ocio, la distracción o la diversión pública, articulando una conexión física e intersubjetiva entre los espacios ${ }^{4}$. Dicho de otro modo, la entretención popular no estaría basada en un único espacio (como la chingana) sino que se diversifica en un conjunto de lugares que se explican como un sistema, no como un territorio único, donde los individuos circulan de manera discontinua. Desde este punto de vista, la pregunta por qué otros lugares pudieron haber cumplido funciones similares a la chingana es relevante $o$, invirtiendo el argumento, la pregunta por qué circuitos de diversión integró la chingana es esencial para comprender el mapa geofísico de los hábitos culturales que la historiografía y la musicología han estudiado de manera parcial, generando una suerte de "hermenéutica monoespacializada" de la cultura popular ${ }^{5}$.

Algunos documentos muestran que durante el siglo XIX hubo otros espacios que tuvieron prácticas similares a la chingana, donde baile, alcohol o comida se pudieron realizar de modo frecuente o infrecuente. Aunque muchos de los autores y autoras citadas en este artículo reconocen la existencia de estos lugares como espacios de diversión (e incluso citan fuentes referidos a ellos), estos no son incluidos al momento de hacer un balance general de las diversiones populares, ya sea por falta de información sistemática, por la carencia de una teoría del espacio o por cierta indiferencia a mostrar el circuito de diversiones sin alcohol. Excluyendo los espacios más conocidos de la sociabilidad como bares, chincheles, cafés, cantinas o cocinerías, en las fuentes estudiadas hemos detectado lugares de entretención con algunos rasgos similares a la chingana (música, baile, venta de alcohol), como billares $^{6}$, canchas de bolas y cafés (con billar), además de otros menos conocidos como casas de títeres, tabladillos ${ }^{7}$, cafés "con canto y baile", baños ${ }^{8}$ y espacios de encumbramiento de volantines ${ }^{9}$, entre otros. Como puede apreciarse en sus nombres, algunos de estos espacios requerían de música para desarrollarse, por lo que la presencia del sonido y, 
consecuentemente, del baile y la escucha, sería un aspecto altamente probable ${ }^{10}$.

Un modo de regulación y obtención de ingresos por parte de los municipios fue el gravamen a la instalación de estos lugares de ocio. Todos los sitios pagaban patentes cuyos precios eran diversos y dependían no solo de su ubicación sino de la naturaleza de la actividad, la ocasión y el lugar a gravar (calle, barrio). En el documento "Razón de las patentes y licencias para diversiones públicas expedidas en enero-marzo, de 1870" 11 , consultado para este artículo, podemos observar que la chingana pagaba menos que otros sitios por instalarse, es decir, tenía una licencia más fácil de obtener, por lo que su masificación era más probable. Otros sitios como billares, cafés, títeres y canchas de bolas pagaban desde $20 \%$ a $100 \%$ más, haciendo difícil su multiplicación entre los empresarios de la entretención. De aquí podemos concluir que la chingana contó con cierta ventaja económica que hizo mayor su presencia en los archivos y, probablemente, menor la de otros espacios similares.

Un lugar interesante y poco estudiado son las canchas de bolas. Con más de un siglo de trayectoria en la capital, hacia 1876 había en Santiago más de 90 canchas de bolas distribuidas a lo largo de las 25 subdelegaciones del departamento de Santiago ${ }^{12}$. La amplia presencia de estos lugares de juego ameritó la redacción de su propia Ordenanza en un momento en que la capital crecía y comenzaba a agrupar a la mayor parte de la población nacional. La revisión de los archivos muestra que estas canchas eran objeto de prohibiciones por exceso de asistentes, obtención ilegal de permisos ${ }^{13}$, "excesos" 14 y "diversiones inocentes", entre otras razones, cuestiones que se atribuyen frecuentemente a las chinganas y que aquí encontramos cotidianamente ${ }^{15}$. Del mismo modo, el pueblo que asistía a ellas -así como a reñideros, baños o loterías- parece no haber sido distinto al que asistía a las chinganas. En una circular enviada a los subdelegados de la capital el 23 de enero de 1856 por el señor Manuel Valenzuela Castillo, intendente y gobernador de la provincia de Santiago, se lee con claridad que el pueblo asistente a las canchas era objeto de las mismas críticas que se hacían al público de las chinganas, como ociosidad y embriaguez:

"Sobrados [i] notorios son los males que la embriaguez i ociosidad emanan i también es evidente que ambos vicios se adquieren casi siempre al rededor o en el centro de esas casas de diversiones públicas denominadas, chinganas, canchas de bolas, etc; que si bien son por desgracia toleradas por disposiciones vigentes, preciso es con todo cohartar en lo posible sus efectos y no consentir que se exceden de aquello que terminantemente se les permite... Los días festivos son los únicos en que legalmente pueden funcionar los establecimientos en que me ocupo y sin embargo, por una relajación funesta del permiso, no solo se mantienen abiertos dichos establecimientos, los días indicados y hasta horas incompetententes sino y también en días lunes y aún martes, en algunos puntos por tolerancia indevida..."16

De estas reflexiones anteriores podemos colegir que las canchas de bolas, así como otros espacios, poseían un funcionamiento, ambiente y legislación no muy distinto al aplicado a las chinganas del siglo XIX. Extrapolando las conclusiones que Silva obtiene para las chinganas, podemos pensar que también habrían sido un "espacio aglutinador que atrae a los sujetos para reunirse y desarrollar sus propias formas de sociabilidad y con ello reconocerse e identificarse" (Silva 2014: 20).

\section{Conclusiones}

En el presente texto he intentado mostrar que la chingana fue un espacio fundamental para el estudio de la cultura popular chilena del siglo XIX que, sin embargo, se consolidó recientemente como objeto de estudio académico. A partir del destacado trabajo realizado por historiadores/as de la cultura y musicólogos -especialmente desde la década de los 90- la chingana se convirtió en paradigma para el estudio de la cultura debido a la abundante información existente en los archivos y la necesidad de controlarla y regularla económica y legalmente. Su expansión como objeto de estudio, empero, también mostró una ausencia de teorías del espacio para comprender el apego a los lugares de diversión y la relación entre estos en el contexto de las entretenciones decimonónicas. La presencia en los archivos de otros sitios con características similares a la chingana-como billares, canchas de bolas, títeres, tabladillos, cafés con canto y baile, baños y volantines- indica que las diversiones 
públicas de esta época fueron más diversas y no estaban únicamente centradas en ella. El hecho de no incluirlas regularmente en el análisis revela, en este sentido, el carácter hipomnémico que ha tenido el archivo en la concepción de la cultura popular santiaguina.

En este contexto, considero que la canonización de la chingana ha servido para centrar el foco en ciertos aspectos del archivo por sobre otros, dejando en segundo plano, pero no excluyendo del todo, la distribución geográfica de otras formas de diversión. La consecuencia de ello ha sido la aparición de una suerte de "hermenéutica monoespacializada" de la cultura popular y la ausencia de un debate historiográfico de la espacialidad de dicha cultura, es decir, una homogeneización de la cultura expresiva y los espacios de diversión. Para evitar esto creo necesario comprender los espacios de diversión como circuitos de cultura "relacionales", de manera de no aislarlos y concebir al sujeto que en ellos habita de manera "monosituada". Como expresa Castillo, los sujetos urbanos del Chile decimonónico no habitan un solo lugar, sino que tienen una manera de vivir relacional, deslocalizada y precaria en la que cualquier cristalización estructural de su modo de vida "es fluctuante, aleatorio[a], fortuito[a]" (Castillo 2008: 43). Del mismo modo, considero que una ampliación de la mirada respecto de estos espacios -que considere experiencias significativas dentro de un circuito- es una opción atractiva que podría integrar lo exterior y la "actividad cognitiva y corporalizada" de los sujetos, superando en una medida razonable los marcos legales y la estricta disciplina del archivo.

\section{Referencias Citadas}

Acevedo Hernández, A.

1953 La cueca: orígenes, historia y antología. Santiago de Chile: Nascimento.

Aguilar Díaz, M. Á.

2012 "Antropología urbana y lugar. Recorridos conceptuales". En A. Giglia y A. Signorelli (Eds.), Nuevas topografías de la cultura (pp. 113-144). México, D.F.: Universidad Autónoma Metropolitana. Juan Pablos editor.

Appadurai, A.

1996 Modernity at Large. Cultural Dimensions of Globalization. Minneapolis: University of Minnesota Press.

Banerjee, Sumanta 1989 The parlour and the streets: elite and popular culture in nineteenth century Calcutta. Calcutta: Seagull Books.

Beard, D., y Gloag, K.

2005 Canon. En David Beard y Kenneth Gloag (Eds.), Musicology: The Key Concepts (pp. 32-34). New York: Routledge Key Guides.

Bloom, H.

1995 El canon occidental. Barcelona Anagrama.

Boutin, Aimée

2015 City of Noise. Sound and Nineteenth-Century Paris. Urbana, IL: University of Illinois Press.

Bowen Silva, M.

2016 "Distraer y gobernar: Teatro y diversiones públicas en Santiago de Chile durante la era de las revoluciones (17801836)". Historia (Santiago), 49(1), 27-56.

Claro Valdés, Samuel, Peña Fuenzalida, Carmen, y Quevedo

Cifuentes, María Isabel

1994 Chilena o Cueca Tradicional de Acuerdo con las Enseñanzas de Don Fernando González Marabolí. Santiago de Chile Universidad Católica de Chile.

Connell, John, y Gibson, Chris

2003 Sound Tracks: popular music, identity and place. London: Routledge.
Connell, John, y Gibson, Chris

2004 "World music: deterritorializing place and identity". Progress in Human Geography 28 (3): 342-361. doi: 10.1191/0309132504ph493oa.

Cornejo, Tomás, Salinas, M., Prudant, E. y Saldaña, C. 2007 ; Vamos remoliendo mi alma!. La vida festiva popular en Santiago de chile 1870-1910. Santiago de Chile: LOM Ediciones.

Derridá, Jacques

1997 Mal de archivo. Una impresión freudiana. Madrid: Trotta.

Donoso Fritz, K.

2009 "Fue famosa la chingana..." Diversión popular y cultura nacional en Santiago de Chile, 1820-1840. Revista de Historia Social y de las Mentalidades, 1(XIII), 33.

Durand, Luis

1954 "Interpretaciones de la cueca". En Viaje, 251, 18-20.

Garrido, Pablo

1943 Biografía de la cueca (Primera edición ed.). Santiago de Chile: Ediciones Ercilla.

Garrido, Pablo

1976 Biografía de la cueca (Segunda ed.). Santiago de Chile: Editorial Nascimento.

Garrido, Pablo

1979 Historial de la cueca. Valparaíso: Ediciones Universitarias de Valparaíso.

Giglia, Ángela

2012 "Sentido de pertenencia y cultura local en la metrópoli global”. In Á. Giglia y A. Signorelli (Eds.), Nuevas topografías de la cultura (pp. 145-174). México, D.F.: Universidad Autónoma Metropolitana. Juan Pablos editor.

Goicovic Donoso, I.

2005 "Ámbitos de sociabilidad y conflictividad social en Chile tradicional: Siglos XVIII y XIX". Revista Escuela de Historia, 4 (enero/diciembre), 23-50.

Izquierdo, J. M., Jordán, L., y Torres, R.

2016 Zamacuecas de papel. Santiago: Autoedición. 
Leyshon, Andrew, Matless, David, y Revill, George, eds. 1998 The Place of Music. New York: The Guilford Press.

Merino, Luis

2006 "Canon musical y canon musicológico desde una perspectiva de la música chilena". Revista Musical Chilena, $L X$ (205), 26-33.

Pereira Salas, Eugenio

1941 Los Orígenes del Arte Musical en Chile. Santiago de Chile: Publicaciones de la Universidad de Chile.

Plath, Oreste

1965 "Las chinganas". En Viaje, 378(Abril), 20.

Plath, Oreste

1970 14/9/1970 "La cueca, nuestro baile nacional". Rosita, 1137, 32-33.

Plath, Oreste

2014 Los juegos en Chile. Aproximación histórica-folclórica. Edición corregida y anotada de Karen Müller Turina. México D.F.: Fondo de Cultura Económica.

Purcell Torretti, Fernando

1998 "Una aproximación a las diversiones populares en el Norte Chico. Las chinganas en Copiapó, 1850-1860". Revista Chilena de Historia y Geografia, 164, [127]-156.

Purcell Torretti, Fernando

2000 "La chingana como espacio privado de diversión popular. Colchagua 1850-1880". Lo público y lo privado en la historia americana (pp. 197-224). Santiago de Chile: Fundación Mario Góngora.

Purcell Torretti, Fernando

2007 "Discursos, Práticas e Atores Na Construção do Imaginário nacional chileno 1810-1850". In M. A. Pamplona \& M. E. Mader (Eds.), Revoluçoes de independéncias e nacionalismos nas Américas. Região do Prata e Chile (Vol. I, pp. 173-213): Editora Paz e Terra.

Ramón, Armando de

1978 "Santiago de Chile (1850-1900). Límites urbanos y segregación espacial según estratos”. Revista Paraguaya de Sociología, XV (42-43), 253-276.

Rico, S.

2009 "De lo popular a lo nacional en el Chile decimonónico: la chingana como un espacio de encuentro y diferenciación en torno a la nación". En Nación y nacionalismo en Chile. Siglo XIX. Santiago: Centro de Estudios Bicentenario.

Rodríguez, Z.

1875 Diccionario de chilenismos. Santiago: Imprenta El Independiente.

Salazar, G., y Pinto, J.

1999 Historia Contemporánea de Chile I. Estado, Legitimidad, Ciudadanía. Santiago de Chile: Ediciones LOM.

Salazar, G., y Pinto, J.

1999 Historia Contemporánea de Chile II. Actores, Identidad y Movimiento. Santiago de Chile: Ediciones LOM.

Salinas Campos, M.

2000 “ ¡Toquen flautas y tambores!: una historia social de la música desde las culturas populares en Chile, siglos XVI-XX LIV”. Revista Musical Chilena, LIV(193), 45-82.

Silva, Jimena

2014 "La Chingana: espacio de construcción y reconstrucción de los sujetos populares (1820-1850)". Tesis para optar al grado de Licenciado en Historia, Departamento de Ciencias Históricas de la Universidad de Chile Facultad de Filosofía y Humanidades.

Spencer-Espinosa, Christian

2007a "Canon discursivo e imaginario cultural: la zamacueca como representación de lo nacional en Chile durante el siglo XIX”. Diploma de Estudios Avanzados en Historia y Ciencias de la Música, Universidad Complutense de Madrid. Spencer-Espinosa, Christian

2007b "Imaginario nacional y cambio cultural: circulación, recepción y pervivencia de la zamacueca en Chile durante el siglo XIX". Cuadernos de Música Iberoamericana 14 (Noviembre, Segunda Época): 143-176.

Spencer-Espinosa, Christian

2009 "Apología del mestizaje, exaltación de la nacionalidad. El papel del canon discursivo en la discusión sobre la etnicidad de la zama(cueca) chilena". Trans (13). Retrieved from http://www.sibetrans.com/trans/articulo/63/ apologia-del-mestizaje-exaltacion-de-la-nacionalidadel-papel-del-canon-discursivo-en-la-discusion-sobre-laautenticidad-y-etnicidad-de-la-zama-cueca-chilena

Spencer-Espinosa, Christian

2017 "Más allá del folclore. La producción social del espacio a través de la cueca urbana en Santiago de Chile (20002010)". ArtCultura 19 (34): 88-105. doi: http://dx.doi. org/10.14393/ArtC-V19n34-2017-1-06.

Tapia, Verónica

2013 "El concepto de barrio y el problema de su delimitación: aportes de una delimitación cualitativa y etnográfica". Bifurcaciones 12: 1-12.

Taylor, Diana

2017 El archivo y el repertorio: el cuerpo y la memoria cultural performática en las Américas. Santiago: Ediciones Alberto Hurtado.

Torres Alvarado, Rodrigo

2001 Cueca, cuequeros et société à Santiago (Chile) au XXème siècle. (Diplôme d'études approfondies), Université de Paris VIII, Paris.

Torres Alvarado, Rodrigo

2008 Zamacueca a toda orquesta. Música popular, espectáculo público y orden republicano en Chile (1820-1860). Revista Musical Chilena, LXII (209), 5-27. doi:10.4067/ S0716-27902008000100001

Torres Paredes, Henry

2019 "Del tejido vegetal al tejido social: La Ramada, la Chingana y la Fonda en Santiago hasta el siglo XIX". Tesis para optar al grado de Magíster en Arquitectura, Pontificia Universidad Católica de Chile.

Valenzuela Márquez, J.

1992 "Diversiones rurales y sociabilidad popular en Chile central: 1850-1880". Formas de Sociabilidad en Chile 1840-1940 (pp. 369-391). Santiago de Chile: Fundación Mario Góngora.

Vega, Carlos

1953 La zamacueca (cueca, zamba, chilena, marinera). La zamba antigua. Historia, origen, música, poesía, coreografía (Vol. XIX). Buenos Aires: Julio Korn.

Wissmann, T.

2014 Geographies of urban sound. Surrey and Burlington: Ashgate.

Zapiola Cortés, J.

1974 Recuerdos de treinta años (1810-1840) (Edición presentada por Guillermo Blanco ed.). Santiago: Zig-Zag.

\section{Fuentes}

Archivo Nacional, Intendencia de Santiago.

Archivo Nacional, Municipalidad de Santiago. 


\section{Notas}

$1 \quad$ Se revisaron archivos de la Intendencia de Santiago (40 volúmenes), Municipalidad de Santiago (44 volúmenes), Archivo Judicial (sin número) y Consejo de Estado (4 volúmenes). En concreto, se hizo una selección y lectura a 152 manuscritos existentes en solicitudes de negocios, permisos, comentarios y documentos relativos a ordenanzas y acuerdos presentes en el archivo de la Intendencia y de la Municipalidad. A su vez se consultaron patentes y licencias de diversiones públicas presentes en tesis y libros, pero especialmente en fuentes originales, donde encontramos menciones a billares, canchas, chinganas, cafés, títeres, lotería, reñideros de gallos, rancheros, teatros y juegos diversos, algunos de estos son citados en este texto. El trabajo principal de revisión fue realizado por Camilo Plaza entre 2016 y 2017 y luego complementado por los responsables del proyecto en 2018 y 2019. Para más información véase Sáez (2019).

2 Fuera del campo de la historia es pertinente señalar la introducción escrita por el músico y cronista Mario Rojas al libro del poeta popular Hernán Núñez Oyarce, Poesía popular y cuecas (1997), donde relaciona la vida "pendenciera" del sujeto popular (el roto) con las chinganas.

3 Vale la pena resaltar el trabajo de Torres (2019) quien estudia desde la arquitectura la ramada, la chingana y la fonda como espacios contenedores de la sociabilidad popular. Basándose en el trabajo de Salazar, Valenzuela, Purcell y Donoso, principalmente, considera que la chingana fue un factor de "integración social" que consiguió evidenciar procesos de cambio de la sociedad chilena, especialmente aquellos orientados a la construcción de una identidad nacional. En este tenor considera las chinganas como "artefactos arquitectónicos de integración social, principalmente para el bajo pueblo, donde se alternaron una serie de eventos, prácticas, conflictos y tradiciones en torno al ocio; es decir, relaciones sociales que graficaban con cierta nitidez los procesos de cambio en la sociedad chilena, plasmadas en los espacios de diversión popular" (p. 11).

4 Existe abundante literatura acerca de este tema. Para casos de espacio, cultura y sonido en el siglo XIX véase Banerjee (1989) y Boutin (2015); para un debate de la relación entre espacios y ciudad, véase Leyshon et al (1995) y Connell y Gibson (2003 y 2004); y para una teoría específica de la relación entre música y espacio aplicada al caso chileno, considérese Spencer (2017).

5 Una excepción a esta omisión de la espacialidad la constituye el libro ; Vamos Remoliendo mi alma! (Cornejo et al (2007), donde se aborda la vida festiva popular en Santiago de Chile entre 1870 y 1910, incluyendo una cartografía de dichos espacios. Este valioso libro, sin embargo, no menciona con detalle las fuentes en las que está basado, por lo que posee un carácter más didáctico que historiográfico.
6 Un ejemplo es Robustiano [Vera], ["Billares en Mercado de San Diego"], Archivo Nacional, Municipalidad de Santiago, volumen 283, Solicitudes, fjs. 18-19, junio de 1879, pp. 12-13, donde se señala la situación de los billares de la Municipalidad de Santiago.

7 Véase [Construcción de Tabladillo], Archivo Nacional, Municipalidad de Santiago, volumen 273, fjs 454, 27 de septiembre de 1877, p. 3, donde se señala que "Con fecha de hoi he decretado, con cargo a la partida de imprevistos a pagar por la tesorería municipal la suma de ochenta pesos a don José L. Muñoz por el tabladillo que construyó para el baile popular en la Alameda de las Delicias".

8 Véase Jacinto Núñez, [Sobre los baños públicos], Archivo Nacional, Municipalidad de Santiago, volumen 217, 22 de junio de 1867, pp. 6-9.

9 Véase [Solicitud de Negocios en El Arenal], Archivo Nacional, Municipalidad de Santiago, volumen 183, sin número, 18 de octubre de 1858, p. 2-4.

10 Otros lugares de diversión pública mencionados en las fuentes que hemos revisado - de los cuales tenemos menos información-son los bares, chincheles, bodega de vinos o licores, cantinas, baratillos, cigarrerías, puesto de paso, bodegas y restaurantes. Estos sitios tuvieron un tipo de gravamen específico, lo que indica que el Estado reconoció su importancia del mismo modo que lo hizo con la chingana, esto es, como un insumo para la entretención del bajo pueblo.

11 Véase Archivo Nacional, Municipalidad de Santiago, volumen 234, enero-marzo de 1870. "Razón de las patentes y licencias para diversiones públicas expedidas en enero-marzo de 1870", folio 2-15; y también "Razón de las patentes para canchas de bolas y palitroques espedidas en agosto de 1862", Archivo Nacional, Municipalidad de Santiago, V. 319, páginas 2-16. Silva (2014) menciona varios de estos documentos en más de siete ciudades del país.

12 [Ordenanza de canchas de bolas], Archivo Nacional, Municipalidad de Santiago, Vol. 283, Ordenanzas y acuerdos, N507, folios 5-7, 1876.

13 [Ayudante de la Intendencia otorga permisos a una mujer para establecer una cancha de bolas en la cañadilla], Archivo Nacional, Intendencia de Santiago, Volumen 1, $\mathrm{N}^{\circ} 1$, fjs. 309, 3 de enero de 1820, páginas 53-54.

14 [Solicitud de prohibición de juegos de bolos, loterías y otros]. Archivo Nacional, Intendencia de Santiago, Volumen 1, $\mathrm{N}^{\circ} 120$, fjs. 50, 30 de septiembre de 1817.

15 Plath (2014: 296-298) menciona varias restricciones que tuvieron las canchas debido a "los excesos que se cometían en las apuestas" (p. 296).

16 "Sobre los males de la ociosidad y la embriaguez". Archivo Nacional, Municipalidad de Santiago, Boletín de Ordenanzas y Disposiciones, 1860, pp. 95-96. 